\title{
Engaging and Empowering Parents of Children with Down Syndrome-The Role of Parents Support Group
}

\author{
Asrul Abdul Wahab ${ }^{1}$ and Ezura Madiana Md. Monoto ${ }^{2}$ \\ ${ }^{1}$ Department of Medical Microbiology \& Immunology, Faculty of Medicine, Universiti Kebangsaan Malaysia \\ Medical Centre, Cheras, Kuala Lumpur. ${ }^{2}$ Department of Family Medicine, Faculty of Medicine, Universiti \\ Kebangsaan Malaysia Medical Centre, Cheras, Kuala Lumpur.
}

\begin{abstract}
Children with Down syndrome are known to have intellectual disability, developmental milestone delay and may also have associated medical conditions. Having a child with Down syndrome could be physically and emotionally challenging to the affected family members. The impact on a family can be multifaceted which can alter the family dynamics and harmony. Most parents felt inadequate with the information given by the healthcare providers. Parents support group plays an important role to support and provide information and resources to other parents of children with Down syndrome. The knowledge and experience on raising the children with Down syndrome are shared with the new parents. This includes the importance of Early Intervention Program (EIP), inclusive education, the benefits of People with Disability card, sharing success story of people with Down syndrome and providing emotional support to the family to boost their confidence and keeping up their positive spirit in raising their children, regardless of their religions and beliefs. Apart from that, we also organize and participate in activities to raise public awareness, advocating for the rights, inclusion and well being of people with Down syndrome, through social and mass media and annual celebration of World Down Syndrome Day on the $21^{\text {st }}$ March. We promote the benefits of inclusive environment so that people with Down syndrome are able to enjoy full and equal rights on an equal basis with other people; enabling them to live, work and participate with confidence and individual autonomy, fully included in society alongside their friends and peers. As healthcare professionals and parents of a child with Down syndrome, we are sharing our own experiences in engaging with other parents of children with Down syndrome to understand the issues and concerns, sharing resources available around them and ways to support them throughout the journey of raising a child with Down syndrome.
\end{abstract}

Keywords: Down syndrome, parent support group, parent-to parent support

\section{INTRODUCTION}

Raising a child with either a genetic condition, congenital anomaly or other chronic medical problems challenges a family not just physically but emotionally as well. Down syndrome, the most common of chromosomal abnormalities; is known to have intellectual disability, developmental delay and may also have associated medical conditions such as congenital heart disease, duodenal atresia, hypothyroidism, vision and hearing problems.

The birth of a child with Down syndrome is likely to affect the family system in many ways, which include social, emotional, cognitive and behavioral processes that influence the functioning of a family. ${ }^{1}$ Often they are vulnerable to multiple demands and commitments that require individual and family adaptation. ${ }^{2}$ Parents of children with Down syndrome showed pessimism about the future of their children especially about problems that may

Asrul Abdul Wahab,

Department of Medical Microbiology \& Immunology, Faculty of Medicine,

Universiti Kebangsaan Malaysia Medical Centre,

E-mail: saw@ppukm.ukm.edu.my arise when they reached adulthood. ${ }^{3}$ In the initial phase, they may have uncertainties about their children's development and the prospects of early education for their children.

Although children with Down syndrome have a schedule of appointments with multidisciplinary healthcare providers concerning their health, growth and development, often parents feel inadequate dealing with all the information provided. Sometimes the healthcare providers are unable to provide more time to discuss about the condition thus the rapport between parents and healthcare providers cannot be established. This factor contributes to parents holding back and not forthright in asking more questions about the condition of their child.

There are reports concerning parental dissatisfaction with the process of dissemination of information in which the information given is inaccurate and outdated. ${ }^{4}$ They also felt that healthcare providers could not provide emotional and social support that they needed. They felt comfortable and looked forward to speak to another family of a child with Down syndrome. The issues that are important and highlighted by the parents include how to cope with a child with Down syndrome and how to help the siblings to cope. ${ }^{5}$ Questions on whether their life would return to 
normal, how to deal with multiple disciplines' appointments and whether or not a child with Down syndrome is able to cope with his or her life are also highlighted among these parents. ${ }^{5}$

As such, parent-led support group plays an important role to assist other parents and to share with them about living with a child with Down syndrome. With the basis of volunteerism, the goals of parents support groups include friendship and support, provision of information, sharing experiences and advocacy for better services. ${ }^{6}$

\section{Down Syndrome Parents Support Group in Malaysia}

In Malaysia, there are a few parents support groups for Down syndrome that parents of children with Down syndrome are encouraged to join. Most groups are voluntary; some are registered under the Registry of Societies (ROS) Malaysia, some are as part of the chapter of Non Governmental Organizations (NGO) and some are established online via social media platforms.

At Kiwanis Down Syndrome Foundation National Centre (KDSF NC), Petaling Jaya, Malaysia, which is an NGO, the Parents Support Group (PSG) was formed as part of the chapter of the organization. KDSF NC is one of the facilities that provides early intervention program (EIP) for children with Down syndrome, from the age of 2 months up to 6 years old.The services involved facilitating the development of gross and fine motor skills, assisting with oral-motor feeding problems, facilitating selfhelp skills (feeding, dressing, grooming, etc) and facilitating play and leisure skills.

PSG in KDSF NC works hand in hand with the management of the centre to provide peer counseling and support to new parents who may need them. Students who are enrolled here are multiracial with different religions and beliefs. We focus and address issues that concern the parents, particularly health and milestones development of children with Down syndrome, the importance of EIP, applying for Orang Kurang Upaya (OKU) or Person with Disability card and its benefits, inclusive education and sharing other resources on services and facilities that would benefit our children with Down syndrome. As healthcare professionals who have children with Down syndrome, we often become the point of reference for the parents and the centre asking on health issues concerning their children/students.

PSG KDSF NC also organizes activities, talks, family gatherings and special meetings to plan and handle issues related to Down syndrome. Annually, services from general hospital such as Ear, Nose and Throat (ENT) Department Hospital Selayang arrange for ENT and audiology assessment and Paediatric Dental Department Hospital Kuala Lumpur for dental health check invited to provide care for our children at KDSF NC. Experts are called to give talks to parents on issues that would benefit both parents and children with Down syndrome such as speech and language skills, behavioral issues and promoting safe 'babywearing' in children with special needs. Parents give full support and participation to such events. The importance of having regular appointments with multidisciplinary healthcare providers at certain intervals such as Developmental Paediatrician, Ophthalmologist, ENT Specialist, Speech Language Pathologist, Audiologist and Paediatric Dentist is emphasized regularly to the parents.

Apart from that, providing emotional support to parents and sharing experience sessions are done in groups of parents via casual meetings or communications through Whatssap $®$ or Facebook $₫$. This enables parents to interact with those who share the same experiences and challenges and help to allay their worries. It also helps them to boost their confidence and keeping up their positive spirit in raising their children, regardless of their religions and beliefs.

PSG KDSF NC is also actively involved in organizing and participating in activities and events to raise public awareness on Down syndrome. In 2014, in conjunction with 25th KDSF NC anniversary and the launch of coffee table book Unlabel to Understand, which featured the life story and achievements of 26 students and ex-students of KDSF NC, PSG KDSF NC had the opportunity to invite other parents, family, friends and the public to know more about people with Down syndrome, to share experiences and to raise fund for the centre.

Creating public awareness is also done through mass media, by appearing on national television and radio programme and also via newspaper interviews, where discussions and dialogues about Down syndrome in general and ways to support people with Down syndrome and eradicating stigmas and misconceptions about the condition were held. Promotion on World Down Syndrome Day is usually done concurrently during our appearance, in which we invite the public to join the annual celebration on $21^{\text {st }}$ March so that the society is able to see how people with Down syndrome live and participate in the community alongside with family, friends, peers and public. In this event, PSG KDSF NC advocates for the right, inclusion and well-being of people with Down syndrome. We also write in the newspapers, magazines and reputable websites highlighting issues on Down syndrome and educating the public to respect the rights of people with Down syndrome as they would towards typical people.

Apart from being involved as part of the chapter of an NGO, we also participated in a parents support group established via social media platform. The group, Bunga-Bunga Syurga (Anak-Anak Sindrom Down) was established in 2012 by a group of parents of children with Down syndrome from all over Malaysia. We found that many parents were not aware of the importance of EIP and the 
registration of the $O K U$ card and its benefits; hence those issues are frequently discussed and highlighted in the group. Besides sharing evidencebased information on therapies for children with Down syndrome and important resources for EIP, the group becomes a platform for parents to share success stories of the children that lifted up the spirits and give positive vibes of other parents in raising their children with Down syndrome. Aside from providing emotional and social support, the group also organized fundraising for families whose children succumbed to illness or those who were critically ill.

Being attached to a tertiary teaching hospital, we also act independently and established a network with the Developmental Paediatricians to provide support and information to parents who bring their child with Down syndrome for follow-ups at the Child Development Centre (CDC). Referrals from new parents in Neonatal Intensive Care Unit (NICU) or Postnatal wards were also accommodated at our convenience, most of the time to comfort them at their most difficult time dealing with the diagnosis they just received. In this setting, too much information would overwhelm them, thus follow up on their conditions, well-being and adaptation are made via telephone call or Whatssap®. Subsequently these parents are referred to other parents support group as mentioned above.

Searching for information on promoting inclusive environment for our children with special needs has led us to Anne Subashini Sivanathan, a well-known inclusive education lecturer and advocate in Malaysia. With a group of volunteers, she founded The Inclusive Outdoor Classroom, where they organized sessions for children with special needs to come together with typically developing children to learn and play side by side. In the group, the varieties of children with special needs including Down syndrome, autism spectrum disorder, cerebral palsy and others are supported and integrated with normally developing children in both outdoor and indoor activities. Such efforts create opportunities for parents to bring their children to be included into the society without being misunderstood and judged by others and enable normally developing children to understand children with special needs better.

\section{CONCLUSION}

From our observation and experience, involvement in parent-led parents support group has empowered them to gain increased skills, develop a sense of power and of belonging amongst the parents of children with Down syndrome. The benefits include connecting with each other and providing emotional support and skills to deal with day-to-day issues and challenges in raising a child with special needs. Parents may gain ideas from other experienced parents on how to handle situations and sharing tried and tested methods. Information on services, facilities and resources in the community are often shared for the benefits of the child and their family. For the parents, the support group is a safe place where they feel they belong and where they can have their issues and problems heard without judgment.

\section{ACKNOWLEDGEMENT}

Authors thank the members of Parents Support Group Kiwanis Down Syndrome Foundation National Centre for their inputs in preparing this work. Authors would also thank the Dean and Director of Hospital Canselor Tuanku Muhriz, Universiti Kebangsaan Malaysia Medical Centre for the support given.

\section{REFERENCES}

1. Barnett D, Clements M, Kaplan-Estrin M, Fialka J. Building New Dreams: Supporting Parents' Adaptation to Their Child with Special Needs. Infants and Young Children. 2003;16(3):184200.

2. Hsiao CY, Van Riper M. Individual and family adaptation in Taiwanese families living with Down syndrome. J Fam Nurs. 2011;17(2):182201.

3. Van Riper M, Ryff C, Pridham K. Parental and family well-being in families of children with Down syndrome: a comparative study. Res Nurs Health. 1992;15(3):227-35.

4. Van Riper M, Choi H. Family-provider interactions surrounding the diagnosis of Down syndrome. Genet Med. 2011;13(8):714-6.

5. Muggli EE, Collins VR, Marraffa C. Going down a different road: first support and information needs of families with a baby with Down syndrome. Med J Aust. 2009;190(2):58-61.

6. Law M, King S, Stewart D, King G. The perceived effects of parent-led support groups for parents of children with disabilities. Phys Occup Ther Pediatr. 2001;21(2-3):29-48. 